\section{Augmented intelligence technology. The ethical and practical problems of its implementation in libraries}

Augmented intelligence technology

\author{
Magdalena Wójcik
}

Faculty of Management and Social Communication, Institute of Information Studies, Jagiellonian University, Kraków, Poland

\begin{abstract}
Purpose - The subject of the article is the concept of augmented intelligence, which constitutes a further stage in the development of research on artificial intelligence. This is a new phenomenon that has rarely been considered in the subject literature so far, which may be interesting for the fields of social sciences and humanities. The aim is to describe the features of this technology and determine the practical and ethical problems associated with its implementation in libraries.

Design/methodology/approach - The method of literature review was used. Systematic searches according to specific questions were carried out using the Scopus and Web of Science scientific databases, as well as Google Scholar and the LISTA abstract database.

Findings - The results established that the issue of augmented intelligence has barely been discussed in the field of librarianship. Although this technology may be interesting as a new area of librarian research and as a new framework for designing innovative services, deep ethical consideration is necessary before this technology is introduced in libraries.

Research limitations/implications - The article deals with some of the newest technologies available, and this topic is generally very rarely discussed in scientific publications in either the social sciences or humanities. Therefore, due to the limited availability of materials, the findings presented in the article are primarily of a conceptual nature. The aim is to present this topic from the perspective of librarianship and to create a starting point for further discussion on the ethical aspects of introducing new technologies in libraries.

Practical implications - The results can be widely used in practice as a framework for the implementation of augmented intelligence in libraries.

Social implications - The article can help to facilitate the debate on the role of implementing new technologies in libraries.

Originality/value - The problem of augmented intelligence is very rarely addressed in the subject literature in the field of library and information science.
\end{abstract}

Keywords Augmented intelligence, Emerging technologies, Information technologies, Library services,

Library trends

Paper type Viewpoint

\section{Introduction}

One of the latest, rapidly developing technologies is augmented intelligence, which is considered the next stage in the development of research on artificial intelligence (AI). Augmented intelligence assumes that AI should be a part of a human being and not a separate, technological tool. As M. Sharma pointed out: "Augmented Intelligence means, in general, the use of technology to expand human information processing capabilities (...)” (Sharma, 2019, p. 90).

(C) Magdalena Wójcik. Published by Emerald Publishing Limited. This article is published under the Creative Commons Attribution (CC BY 4.0) licence. Anyone may reproduce, distribute, translate and create derivative works of this article (for both commercial and non-commercial purposes), subject to full attribution to the original publication and authors. The full terms of this licence may be seen at http:// creativecommons.org/licences/by/4.0/legalcode

Author would like to thank Mike Timberlake for proofreading. 
LHT

39,2

436

Unfortunately, there is no one clear definition of augmented intelligence, probably due to the complexity of this phenomenon and its novelty in scientific research. As M. Pasquinelli emphasizes: "Augmented intelligence is an umbrella-term used in media theory, cognitive sciences, neurosciences, philosophy of mind, and political philosophy to cover the complex relation between human intelligence on one side, and mnemo-techniques and computational machines on the other-both understood to be an expansion (also to a social and political degree) of human cognitive faculties" (Pasquinelli, 2015, p. 203). This concept fits well into the issue of transhumanism - the conviction that technology, combined with the development of medical research, biotechnology and genetics, can improve the human condition and increase its potential (Porter, 2017). This is a controversial concept that is worth considering from the perspective of libraries. Therefore, the question should be asked: how much can the transhumanistic augmented intelligence concept affect library services and other areas of libraries' activities, and what might the ethical consequences of such actions be?

The subject of the article is the concept of augmented intelligence analysed as another stage in the development of research on AI. This is a new phenomenon that has rarely been described in the subject literature, and that may be interesting for libraries. The aim is to describe the features of this technology and determine the practical and ethical problems related to its implementation in libraries. The specific intentions include:

(1) comparing the features of augmented intelligence to other social and technological concepts such as transhumanism, AI and augmented reality;

(2) discussing the areas of the actual and potential application of augmented intelligence, as well as describing the potential for augmented intelligence in designing and implementing innovative information services in libraries;

(3) describing the practical problems related to the implementation of augmented intelligence technology in libraries in the context of ethical issues.

The method of literature review was used to establish the state of research (Figure 1).

A systematic search was carried out using selected sources: the well-known Scopus and Web of Science databases, both of which include journals with a high impact factor; Google Scholar, a popular search engine of scientific resources that indexes publications from many

Figure 1.

Research stages

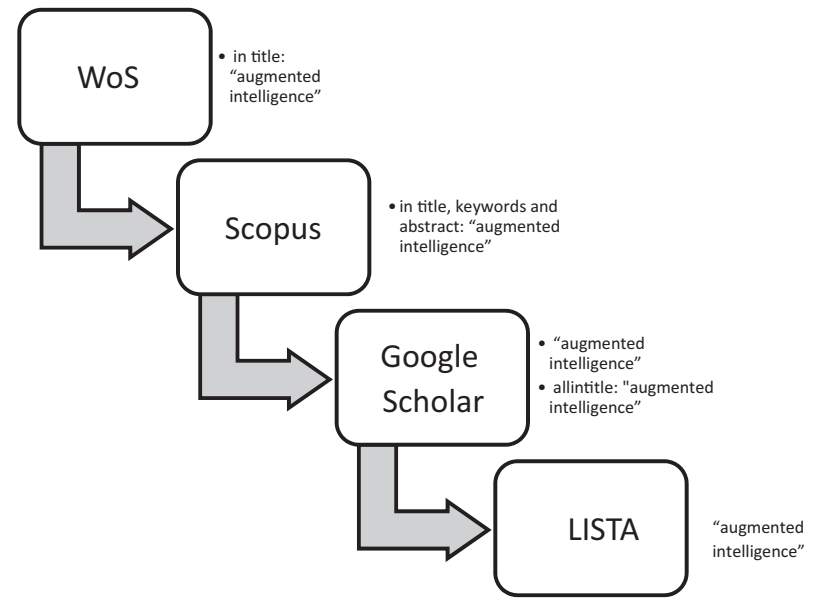

Source(s): own research, 2019 
sources, including less-known ones; LISTA, a specialized abstract database in the field of library and information science. Only papers published between 2010 and 2018 in English, or with at least an abstract and keywords in English, were taken into consideration. It is worth noting that papers on both artificial and augmented intelligence are carried out in many countries, and the results of the research are published in different languages. The author decided to include in the analysis only papers in English, assuming that it is a language known to readers of Library Hi Tech, a journal published in this language, and because of this giving readers the greatest opportunity to read the papers analysed in this article themselves, if they have such a need. The results of literature review were subjected to quantitative and qualitative analysis based on full texts or abstracts and keywords to determine the scope and profile of the existing research on augmented intelligence.

\section{The state of research}

The topic of augmented intelligence is relatively rare in the subject literature (Table 1).

Searches carried out using the Scopus database yielded 37 results, most of them relevant to the topic. The vast majority of these publications came from the fields of computer science, engineering and medicine. Within these disciplines, authors focussed primarily on topics related to the technical dimension of augmented intelligence and the current and potential application of this technology in diagnostic, decision-making and advisory procedures. Publications from other disciplines, such as mathematics or management, were less well represented. The most relevant for this paper were following publications: Augmented intelligence: enhancing human capabilities (Hebbar, 2017); Knowledge-based artificial augmentation intelligence technology: the next step in academic instructional tools for distance learning (Crowe et al., 2017); Augmented intelligence: the Web and human intelligence (Von Ahn, 2013); and Augmented intelligence - the new AI-unleashing human capabilities in knowledge work (Corrigan, 2012). In all of these publications, the authors analysed augmented intelligence in categories that could be considered transhumanistic; thus, they emphasized the value of this technology for human development. Attention was paid to the role of augmented intelligence in increasing the possibilities of acquiring, processing and using information and thus increasing the cognitive abilities of human beings.

It should be noted that in the first half of 2019, the number of publications in the Scopus database on augmented intelligence was the same number as for the entire year of 2018, which may indicate the growing popularity of the topic. The most interesting publications of 2019 include Augmented intelligence: a way for helping universities to make smarter decisions (Sharma, 2019) and A framework for easier designs: augmented intelligence in serious games for cognitive development (Golestan et al., 2018).

The search carried out on the Web of Science database produced 16 results; this was less than in the Scopus database, but all of them were relevant. As with the Scopus search, most of the

\section{Augmented intelligence technology}

\begin{tabular}{llll}
\hline Stage & Database & Query & Results \\
\hline 1 & $\begin{array}{l}\text { Web of } \\
\text { Science }\end{array}$ & in title: "augmented intelligence" & Total number of results: 16 \\
2 & Scopus & $\begin{array}{l}\text { in title, keywords and abstract: "augmented } \\
\text { intelligence" }\end{array}$ & Total number of results: 37 \\
3 & $\begin{array}{l}\text { Google } \\
\text { Scholar }\end{array}$ & $\begin{array}{l}\text { allintitle: "augmented intelligence" } \\
\text { "augmented intelligence" }\end{array}$ & $\begin{array}{l}\text { Total number of results: } 923 \\
\text { Total number of relevant } \\
\text { results: } 33\end{array}$ \\
& LISTA & Total number of relevant \\
& & & results: 3
\end{tabular}

Table 1. Information search processes 
LHT

39,2

papers came from the fields of computer science, engineering and medicine. Interestingly, most of the publications came from conference proceedings and only three results came from journals. This indicates that the subject of augmented intelligence is being discussed in the scientific community but has not yet reached circulation in the main scientific journals, perhaps due to the long review and editorial process applied by prestigious journals. The most interesting work from the point of view of this article was the paper AI 2.0: augmented intelligence (Lisboa, 2018). This article is written from the perspective of computer science and engineering and focusses on the technical aspects of augmented intelligence; however, its broad nature also makes it an interesting area of consideration for the fields of humanities and social sciences.

The search carried out using Google Scholar yielded 923 results; however, after rejecting quotes and patents and narrowing down the results to publications that had the phrase "augmented intelligence" in the title, only 33 relevant results were obtained. These came primarily from the field of computer science and were published mainly in conference materials and (far less frequently) in journals; this shows that the topic is being discussed, but has not yet reached the main scientific circuit. There were also a few papers discussing this subject from the perspectives of medical (Skiba, 2017; Khodadad et al., 2018) and legal sciences (Lui and Lamb, 2018).

It was also established that the subject of augmented intelligence is very rarely discussed in the field of library and information science. A search carried out in the specialized LISTA abstract database provided only three results: two with a moderate degree of relevance regarding the legal aspects of augmented intelligence and one result on the use of augmented intelligence at universities (Hannay, 2014). It is worth emphasizing that mentions of augmented intelligence have sometimes appeared, however, indirectly, in papers devoted to AI. Such publications could be found in the field of library and information science. An example would be papers such as: Through the looking glass: envisioning new library technologies-how artificial intelligence will impact libraries (Fernandez, 2016) or What's trending in libraries from the Internet cybersphere - artificial intelligence and other emerging technologies (Oyelude, 2017). This type of publications, although very interesting and useful in the general understanding of the role of AI in libraries, does not reflect the specifics of augmented intelligence. It seems that this gap in the subject literature should be filled.

It can be concluded that the topic of augmented intelligence is rarely discussed in the subject literature, especially when compared to the related topic of AI, which is very well represented. Augmented intelligence is generally explored in conference materials from the perspective of computer science, engineering and medicine, but it appears less frequently in scientific journals. From the perspective of humanities and social sciences, this represents a gap in the research that should be filled.

\section{Augmented intelligence versus artificial intelligence and augmented reality}

$\mathrm{AI}$ is an interdisciplinary field of knowledge that was initiated in the 1950s and combines the achievements of computer science, cognitive science and logic. It aims to solve complex problems that are beyond the scope of simple algorithms, and it strives to reproduce and refine the functions of the human mind. The hallmark of AI-based programs is the ability to recognize patterns and learn from them in order to develop and improve on their own functionality (Ertel, 2017). AI is used in diagnostic and advisory programmes in the business sector, as well as in medicine, economics and entertainment (e.g. virtual opponents in games such as chess and virtual assistants such as Siri and Alexa), and the areas of its usability are constantly growing (Jiang, 2017; Krishnamoorthy, 2018). Despite the usefulness of AI in society, there remain legal, ethical and practical concerns regarding this powerful technology. Among the most common causes for concern is the fact that autonomous AI solutions might make decisions that are rational but that also might be unethical. Some of these concerns are unjustified and relate to so-called "strong artificial intelligence" - a concept that has yet to be 
implemented in practice and possibly never will be (Bostrom, 2009) - but some of these doubts are justified. It seems that the greatest concern in this context is the loss of human control over external AI agents. One answer to this fear may be the development of augmented intelligence, a concept that assumes that AI is part of a human being and not a separate tool. As E. Crigger and C. Khoury stated: "Augmented intelligence is an alternative conceptualization that focuses on AI's assistive role, emphasizing a design approach and implementation that enhances human intelligence rather than replaces it" (2019) (Table 2). Although the current concept of augmented intelligence is considered to be a new idea, the genesis of this kind of thinking is almost as old as research on AI itself. Augmented intelligence began to develop almost in parallel with AI research in the 1950s, but it was not called augmented intelligence at that time. Instead, other terms were used, such as Intelligence Amplification, Augmenting Human Intellect or Man-Computer Symbiosis (Skagestad, 1993; Biocca, 1996).

Discussions should also include the relationship between augmented intelligence and augmented reality. Although it may seem that the two ideas share only part of their name, it can be argued that the analogies go deeper (Table 2). Both concepts relate to the problem of blurring the boundaries: in the case of augmented reality, this relates to the border between the real world and the virtual world; in the case of augmented intelligence, this relates to the border between $\mathrm{AI}$ and human intelligence. Both concepts also relate to the topic of augmentation: broadening or refining things in the information environment in the case of augmented reality, and doing the same for human cognitive abilities in the case of augmented intelligence.

\section{Augmented intelligence in the context of transhumanism}

In the field of computer science, there is a relative abundance of publications concerning the technical aspects of augmented intelligence. However, from the point of view of library and information science, it is more interesting to analyse this phenomenon in socio-humanistic terms and thus as part of the wider phenomenon of transhumanist considerations.

Transhumanism, a concept often associated with Julian Huxley, explores the far-reaching integration of man and machine in order to improve human capabilities (Huxley, 1968). It can be stated that “(...) transhumanism is an intellectual and cultural movement premised upon the idea that human beings can use science and technology to significantly enhance their capabilities and thereby overcome many of the limitations of human biology" (Huberman, 2018). Generally speaking, this concept assumes that widely understood technologies - in particular, robotics, AI, biological implants and the development of biotechnology - will improve the human condition in the future in terms of health, life expectancy and physical and intellectual abilities (Hays, 2014). The scale of the implementation of transhumanism is broad and may include simple body modifications or advances in genetic research, but also

\begin{tabular}{|c|c|c|c|}
\hline Area of comparison & Augmented intelligence & Artificial intelligence & Augmented reality \\
\hline $\begin{array}{l}\text { Virtuality continuum } \\
\text { scale (Milgram and } \\
\text { Kishino, 1994) }\end{array}$ & In the middle & Closer to virtuality & Closer to reality \\
\hline $\begin{array}{l}\text { Computer-human } \\
\text { interaction }\end{array}$ & $\begin{array}{l}\text { Human and technology } \\
\text { together in symbiosis }\end{array}$ & $\begin{array}{l}\text { Computer and human } \\
\text { separated }\end{array}$ & $\begin{array}{l}\text { Computer and human } \\
\text { separated }\end{array}$ \\
\hline $\begin{array}{l}\text { Required equipment } \\
\text { and/or technology }\end{array}$ & $\begin{array}{l}\text { Human as a part of system; } \\
\text { human as designer or user; } \\
\text { hardware; software }\end{array}$ & $\begin{array}{l}\text { Human only as } \\
\text { designer or user; } \\
\text { computer; software }\end{array}$ & $\begin{array}{l}\text { Human only as designer } \\
\text { or user; mobile device; } \\
\text { mobile application }\end{array}$ \\
\hline
\end{tabular}


LHT

39,2

more extreme ideas such as the physical connection of man and machine, the transfer of consciousness into cyberspace or the quest for eternal life. The concept of transhumanism, especially in its more extreme form, raises much controversy, particularly in the fields of philosophy and bioethics (Hall, 2016; Porter, 2017; Karaman, 2019). It is unclear how far science can go in trying to improve humans without violating ethical boundaries. In many publications, transhumanism has been compared to aspects of Nietzsche's philosophy (Sorgner, 2009; More, 2010; Tuncel, 2017), especially in terms of his overman concept, which was misinterpreted to deplorable effect in the past by certain political movements (e.g. during the Second World War). This is one of the most serious allegations related to the development of transhumanism: the fear of segregating people along the lines of their level of compliance with some arbitrary pattern of excellence. Some authors have also pointed out that transhumanism is based on the cult of progress and technology, an uncritical belief which can therefore mean it neglects other values such as nature and regard for natural human limitations (Frodeman, 2019). On the other hand, advocates of this movement focus on the potential benefits associated with the development of human cognitive abilities that can contribute to progress in many areas, such as improving physical capability, health and longevity through the use of the latest scientific, technical and biological achievements.

The development of augmented intelligence - which significantly expands human cognitive abilities through advanced technology - goes well with the assumptions of transhumanism. Although the development of augmented intelligence can be considered one of the less extreme forms of transhumanism, it is worth widening the perspective to consider how its application might affect social structures. Could the enhancement of humans through augmented intelligence exacerbate the existing digital divide and digital exclusion problems, defined as "the gap between people who do and do not have access to forms of information and communication technology" (Van Dijk, 2017, p. 1)? Would the use of augmented intelligence segregate people and divide them into groups according to the degree of augmentation? This is, of course, a pessimistic vision that might not come to pass, but it should be taken into account. On the other hand, it is unrealistic to expect technological progress to stop due to fear of the digital divide. Instead, the focus should be on responsible management of technological achievements so that they serve the common good; also, effective educational activities should be offered to help close the digital divide. This is obviously not a simple solution, but one that requires the coordinated development of financial, educational and legal controls.

\section{Augmented intelligence - general areas of use and its potential for libraries}

Although the broad application of AI has been well documented, determining the areas of the actual and potential use of this technology is not so easy in the case of augmented intelligence as it is a new and relatively poorly recognized concept. It can be assumed that augmented intelligence will be used wherever AI is used, above all, in diagnostic, prognostic and advisory systems. Generally speaking, augmented reality can be useful wherever increasing the cognitive abilities of a person is vital. As C. G. Harrison pointed out: "(. . .) it should be evident that Augmented Intelligence is a technology capable of extremely broad application, essentially any domain where value can be extracted from very large or diverse collections of information and where there is a need for decision-making in complex situations" (Harrison, 2018, p. 8). This technology may be particularly useful in supporting decision-making processes in, for example, medicine, law, public security, science, industry or business. Potentially, it can also be used in education as a support for teachers and students or in entertainment to produce new types of games (Figure 2).

There are already quite a few papers exploring the possibilities of the use of augmented intelligence in medicine, for example, for supporting diagnostic and decision-making 


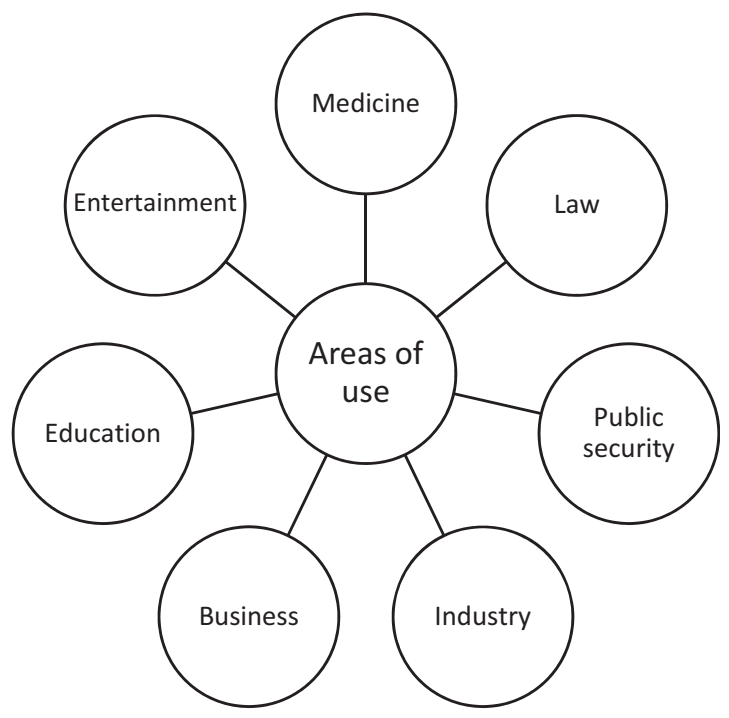

Source(s): own research, 2019
Augmented intelligence technology

441

processes (Khodadad et al., 2018; Arieno et al., 2019). There are also interesting papers on the use of augmented intelligence to increase the accuracy of predictions and therefore decisionmaking processes in the economic and financial sectors (Lui and Lamb, 2018), as well as on the use of this technology in education (Crowe et al., 2017). In all of these areas, it is mainly about using augmented intelligence to increase the cognitive, analytical and decision-making power of specialists from various industries, so that they can better process information and make better decisions based on it, while maintaining full control and autonomy over technology. The advantage of using augmented intelligence over $\mathrm{AI}$ is still relying on man, not just technology, to solve problems and make decisions. It is worth noting that most existing publications are theoretical in nature and describe the potential of augmented intelligence rather than actual examples of implementation. It is difficult to find concrete results of empirical research or case studies, and therefore we can only speculate as to the full range of possibilities with regard to the application of augmented intelligence.

At this stage in the development of advanced intelligence technology, one can only speculate on the scope and manner of its use in librarianship because there is no literature on which such discussions can be based. However, the topic is worth considering because this technology will enter libraries sooner or later. Augmented intelligence can be utilized in all of the five basic areas of library activity: back-office activities (e.g. cataloguing, acquisition of collections, management activities), user services, education, cultural activities, library promotion and PR (Figure 3).

There are already publications describing the potential use of augmented intelligence in education, so it can be assumed that it is also possible for it to be employed in educational activities in libraries. As outlined earlier, augmented intelligence can support the learning of various skills. In this case, it can be assumed that augmented intelligence can support, for example, reading and media education processes for users, as well as the processes of selfeducation and professional development of librarians. Due to the lack of literature and research on this subject, it is difficult to predict how augmented intelligence might affect the functioning of a library as a cultural institution. However, it can be safely assumed that the 


\section{LHT}

39,2

\section{2}

Figure 3.

Augmented intelligence - the potential for library services

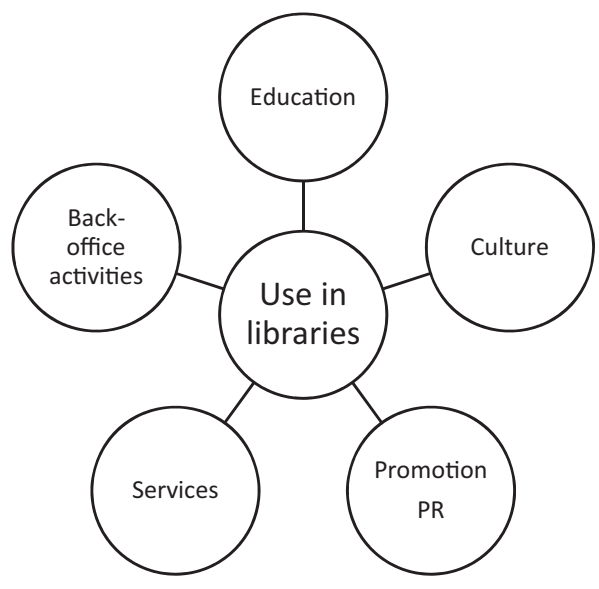

Source(s): own research, 2019

use of the latest technologies is always good for building good relationships with the libraries' audience and can help support the promotion of an institution and its values. In the case of libraries, this means reading, culture and the conscious use of information and media messages. In this context, the potential role of augmented intelligence can be seen in the promotion of cultural activities in libraries. Potentially one of the most interesting uses of augmented intelligence in libraries is in the area of information services. In theory, information retrieval for librarians using augmented intelligence solutions, which allows increasing their natural capabilities in the acquisition, analysis and processing of information, would be better, faster and more efficient in meeting users' information needs. Finally, the possibility of using augmented intelligence to optimize back-office processes has yet to be considered. It seems that this technology could be used, for example, to improve the process of describing and cataloguing resources. With regard to information services, the use of augmented intelligence would increase the speed and accuracy of the process of retrieving information, such as missing bibliographic data or the provenance of information that is necessary for the precise description of resources. It can also be used during decision-making processes in areas, for instance, acquisition of collections or making selection of resources, as well as in performing general library management activities; wherever it is necessary to consider many factors at once and efficiently make difficult decisions. All in all, although it is difficult to precisely determine the potential of augmented intelligence in libraries, a wide range of hypothetical applications would appear to be achievable.

\section{Augmented intelligence - the practical concerns of implementation in the context of ethical problems}

Augmented intelligence stands at the junction of two dynamically developing concepts: AI and augmented reality. The possibilities of applying the computing power of a machine to human cognitive processes and the ability of augmented reality applications to flexibly connect the digital and physical environments create enormous potential for development in many areas of human activity. As is stated in the subject literature, this could improve educational, decision-making, diagnostic, predictive and advisory processes (Crowe et al., 2017; Lui and Lamb, 2018; Khodadad et al., 2018; Arieno et al., 2019) and allow for the better processing of knowledge, thus enabling more effective use of these processes. It is assumed 
that this technology could also have a big and positive impact on library activities in the areas of education, promotion and services, as well as in management and decision-making processes. However, as is always the case with new technologies, it is necessary to consider not just the benefits, but also any potential risks involved. The practical aspects of implementing augmented intelligence in libraries should be rethought in the context of any ethical issues that may arise. This is particularly apparent in the context of the concept of transhumanism, which has already been discussed in this article. Other ethical issues also require consideration: To what extent will the implementation of augmented intelligence solutions bring benefits for library users? How likely is it that it will lead to the stratification of society into "ordinary" and "improved" citizens?

When discussing the practical and ethical considerations of implementing augmented intelligence in libraries, one cannot ignore the financial concerns. In most countries, libraries are public institutions financed from public funds and are therefore accountable for their spending. It is right to question the extent to which the benefits of implementing augmented intelligence justify investing in this type of solution. As K. D. Elsbach and I. Stigliani pointed out, "(...) new technology is viewed, often implicitly, as something wondrous that can change the world" (2019, p. 185), so there is a lot of bias connected with the perception that new solutions are automatically better than old ones, which may not always be true. The issue of serving public interest is particularly worth considering in the case of public institutions. To what extent will a new solution serve all citizens equally, and to what extent will it only serve selected groups? Of course, not all libraries operate on the same basic principles. Some are funded by very specific target groups, for example, company, professional or even scientific libraries; but for libraries used by the general public, these questions are especially important. The mission and ethics related to the deontology of the librarian's profession, therefore, need consideration. One of the main responsibilities of a librarian in any library is to act in the best interests of the user: to correctly assess their needs and to meet their expectations accordingly. This is mentioned in both the ALA and the IFLA librarian's code of ethics (ALA, 2008) (IFLA, 2016). The question is whether the implementation of augmented intelligence is necessary to meet these needs. Due to the diversity of libraries and their funding methods in different countries or even regions, developing a global consensus on what to spend public funds on is not possible. However, it is socially responsible for libraries to take into account the ethical aspects of public funds management when making any decisions.

Another consideration that is both practical and ethical in nature is the issue of processing and securing users' data. Currently, great attention is paid to the responsible management of personal data, as evidenced by the introduction of quite restrictive legal regulations known as the General Data Protection Regulation in the European Union (Regulation, 2016). In terms of protecting data, new technologies pose new challenges that have both legal and ethical dimensions. In general, the use of new technologies has opened up new paths for fraud, scams and data trading. A special threat is created by the use of technologies that track cognitive or decision-making processes, or augmented intelligence, which gathers very personal data, for example, on the functioning of someone's brain. It is worth emphasizing that protecting a users' privacy is not only a legal obligation but also an ethical one. In the literature on this subject, much space is devoted to the legal issues related to data protection in terms of describing an institution's legal obligations and the sanctions related to non-compliance (Bailey, 2018) (Katulić and Katulić, 2017). This topic is definitely less frequently raised from an ethical perspective considering libraries' moral obligations to users. This may be due to existing codes of librarianship ethics, but it is apparent that a clear emphasis on the ethical aspects of legal action is necessary.

One interesting but negative phenomenon discussed by Lui and Lamb (2018) is the potential issue of discrimination and bias within the design and implementation of many technological solutions, including augmented intelligence. This is related to the fact that in

Augmented intelligence technology 
LHT

39,2 many countries, there is a predominance of men, mostly white, working in technology companies as programmers, designers and project managers. As a result, technological solutions are designed, unconsciously or otherwise, based on their own needs, preferences and experiences, thereby creating products tailored to a specific ethnic or gender group to the exclusion of other users. The problem of bias in technology design is increasingly being discussed in many fields of study, such as computer science, philosophy and cognitive science. It needs to be highlighted that this is a very complex and extensive problem requiring a separate discussion, which is only briefly signalled in this article, but must be addressed because of its validity. Bias in technology and the information sphere takes many different forms and varieties and can affect different user groups. For instance, D. Hankerson et al. provide specific examples of poorly designed products and services that have been introduced to the exclusion of specific groups who are unable to use them. As the authors wrote, "We have catalogued a range of incidents where race has adversely affected technology's usability for underrepresented minorities. We will discuss three areas where this has occurred - in sensor design, in algorithms and in interface design" (Hankerson et al., 2016, p. 476). Examples include objects of everyday use, such as a soap dispenser, as well as popular gadgets such as the Apple iWatch. It is worth emphasizing that bias can take different forms and affect different groups of users because of their gender, race, age or social background. Bias in technology is a serious ethical problem, so when implementing augmented intelligence solutions in libraries and elsewhere, special attention should be paid to the inclusiveness of this technology: from providing a project team representative of various gender, age or ethnic groups, to the stage of implementing technology in such a way that it does not exclude anyone.

Discussions in the subject literature on the ethical aspects of implementing artificial and augmented intelligence solutions have been going on for a long time, especially in relation to philosophy, psychology and biology (Hall, 2016; Porter, 2017; Karaman, 2019), but it is still difficult to reach unambiguous conclusions. Some authors are focussed on the benefits associated with expanding human capabilities through technology: they see it as a natural process in which man and machine are in a symbiotic relationship (Corrigan, 2012) (Von Ahn, 2013). Others are concerned about the possible negative social consequences: the division into "better" and "worse" citizens; further development of the digital divide; the risk of the unethical use of this technology, especially in the health and finance sectors (Crigger and Khoury, 2019), (Lui and Lamb, 2018). All in all, it can be concluded that the implementation of augmented intelligence solutions requires caution, prudence and careful oversight of entities that deal with research ethics. It seems that the potential of augmented intelligence to improve human health and cognitive processes is worth developing and testing, but with caution and responsibility.

\section{Conclusions}

Based on the review of the subject literature, it has been established that augmented intelligence has not yet been widely explored in the context of librarianship, although the technology could potentially be of interest in librarian research and as a new framework for designing innovative services. It could also be interesting from the perspective of libraries' educational and promotional activities, as well as in the context of back-office and management activities. However, with regard to the implementation of augmented intelligence in libraries - as with the application of this technology in any field - prudent judgement is recommended to ensure ethical standards are met. As public institutions, libraries are obliged to act in the interests of society: on the one hand, this obliges them to consider the use of any potential new technology, but on the other hand, it also charges them with accepting responsibility for any possible negative outcome. This is not an easy role for libraries, but this is a challenge that libraries will probably face sooner or later. 


\section{Limitations}

The article deals with some of the newest technologies available, and this topic is generally very rarely discussed in scientific publications in either the social sciences or humanities. Therefore, due to the limited availability of materials, the findings presented in the article are primarily of a conceptual nature. The aim is to present this topic from the perspective of librarianship and to create a starting point for further discussion on the ethical aspects of introducing new technologies in libraries.
Augmented intelligence technology

\section{References}

ALA - American Library Association (2008), "Professional ethics", available at: http://www.ala.org/ tools/ethics (accessed 26 November 2019).

Arieno, A., Chan, A. and Destounis, S.V. (2019), "A review of the role of augmented intelligence in breast imaging: from automated breast density assessment to risk stratification", American Journal of Roentgenology, Vol. 212 No. 2, pp. 259-270.

Bailey, J. (2018), "Data protection in UK library and information services: are we ready for GDPR?", Legal Information Management, Vol. 18 No. 1, pp. 28-34.

Biocca, F. (1996), "Intelligence augmentation: the vision inside virtual reality", Advances in Psychology, Vol. 113, pp. 59-75.

Bostrom, N. (2009), "Ethical issues in advanced artificial intelligence", in Schneider, S. (Ed.), Science Fiction and Philosophy: From Time Travel to Superintelligence. John Wiley \& Sons, Hoboke, pp. 277-284.

Corrigan, J.M. (2012), "Augmented intelligence-the new AI-unleashing human capabilities in knowledge work", in Glinz, M. (Ed.), Proceedings of the 34th International Conference on Software Engineering. Piscataway, IEEE Press, Piscataway, pp. 1285-1288.

Crigger, E. and Khoury, C. (2019), "Making policy on augmented intelligence in health care", AMA Journal of Ethics, Vol. 21 No. 2, pp. 188-191.

Crowe, D., LaPierre, M. and Kebritchi, M. (2017), "Knowledge based artificial augmentation intelligence technology: next step in academic instructional tools for distance learning", TechTrends, Vol. 61 No. 5, pp. 494-506.

Elsbach, K.D. and Stigliani, I. (2019), "New information technology and implicit bias", Academy of Management Perspectives, Vol. 33 No. 2, pp. 185-206.

Ertel, W. (2017), Introduction to Artificial Intelligence, Springer, Cham.

Fernandez, P. (2016), "Through the looking glass: envisioning new library technologies how artificial intelligence will impact libraries", Library Hi Tech News, Vol. 33 No. 5, pp. 5-8, available at: https://doi.org/10.1108/LHTN-05-2016-0024 (accessed 15 March 2020).

Frodeman, R. (2019), Transhumanism, Nature, and the Ends of Science: A Critique of Technoscience, Routledge, New York.

Golestan, S., Mahmoudi-Nejad, A. and Moradi, H. (2018), "A framework for easier designs: augmented intelligence in serious games for cognitive development”, Consumer Electronics Magazine, Vol. 8 No. 1, pp. 19-24.

Hall, M. (2016), The Bioethics of Enhancement: Transhumanism, Disability, and Biopolitics, Lexington Books, Lanham.

Hankerson, D., Marshall, A.R., Booker, J., El Mimouni, H., Walker, I. and Rode, J.A. (2016), "Does technology have race?", in Kaye, J. (Ed.), Proceedings of the 2016 CHI Conference Extended Abstracts on Human Factors in Computing Systems. ACM, San Jose, pp. 473-486.

Hannay, T. (2014), "The digital academy and augmented intelligence", Information Today, Vol. 31 No. 10 , p. 25.

Harrison, C.G. (2018), “Augmented intelligence and society”, available at: https://go.aws/3aWhFS2. 
LHT

39,2

Hays, S. (2014), "Transhumanism", Britannica online version, available at: www.britannica.com (accessed 20 June 2019).

Hebbar, A. (2017), "Augmented intelligence: enhancing human capabilities”, in Bhattacharyya, S. (Ed.), 2017 Third International Conference on Research in Computational Intelligence and Communication Networks (ICRCICN), IEEE, Piscataway, pp. 251-254.

Huberman, J. (2018), "Immortality transformed: mind cloning, transhumanism and the quest for digital immortality", Mortality, Vol. 23 No. 1, pp. 50-64.

Huxley, J. (1968), “Transhumanism”, Journal of Humanistic Psychology, Vol. 8 No. 1, pp. 73-76.

IFLA Code of Ethics for Librarians and other Information Workers (2016), available at: https://www. ifla.org/publications/node/11092 (accessed 19 July 2019).

Jiang, F., Jiang, Y., Zhi, H., Dong, Y., Li, H., Ma, S., Wang, Y., Dong, Q., Shen, H. and Wang, Y. (2017), "Artificial intelligence in healthcare: past, present and future", Stroke and vascular neurology, Vol. 2 No. 4, pp. 230-243.

Karaman, F. (2019), "Ethical issues in transhumanism", in Sisman-Ugur, S. and Eby, G. (Eds), Handbook of Research on Learning in the Age of Transhumanism, IGI Global, Hershey, pp. 98-115.

Katulić, T. and Katulić, A. (2017), "Competences, position and role of data protection officers in ensuring library data protection compliance", available at: http://ibrary.ifla.org/id/eprint/2597 (accessed 10 November 2019).

Khodadad, I., Shafiee, J., Wong, A., Kazemzadeh, F. and Arlette, J. (2018), "Deep tissue sequencing using hypodermoscopy and augmented intelligence to analyze atypical pigmented lesions", Journal of Cutaneous Medicine and Surgery, Vol. 22 No. 6, pp. 583-590.

Krishnamoorthy, C.S. and Rajeev, S. (2018), Artificial Intelligence and Expert Systems for Engineers, CRC press, Boca Raton.

Lisboa, P.J.G. (2018), “AI 2.0: augmented intelligence”, in Liu, J., Lu, J., Xu, Y., Martinez, L. and Kerre, E.E. (Eds), Data Science and Knowledge Engineering for Sensing Decision Support: Proceedings of the 13th International FLINS Conference (FLINS 2018), World Scientific Publishing, Singapore, p. 10.

Lui, A. and Lamb, G.W. (2018), "Artificial intelligence and augmented intelligence collaboration: regaining trust and confidence in the financial sector", Information and Communications Technology Law, Vol. 27 No. 3, pp. 267-283.

Milgram, P. and Kishino, F. (1994), "A taxonomy of mixed reality visual displays", IEICE Transactions on Information and Systems, Vol. 77 No. 12, pp. 1321-1329.

More, M. (2010), “The overhuman in the transhuman”, Journal of Evolution and Technology, Vol. 21 No. 1, pp. 1-4.

Oyelude, A.A. (2017), "What's trending in libraries from the internet cybersphere-artificial intelligence and other emerging technologies", Library Hi Tech News, Vol. 34 No. 2, pp. 11-12, available at: https://doi.org/10.1108/LHTN-02-2017-0008 (accessed 14 March 2020).

Pasquinelli, M. (2015), Alleys of Your Mind: Augmented Intelligence and its Traumas, Meson Press, Lüneburg.

Porter, A. (2017), "Bioethics and transhumanism", Journal of Medicine and Philosophy: A Forum for Bioethics and Philosophy of Medicine, Vol. 42 No. 3, pp. 237-260.

Regulation (EU) (2016), "679 of the European parliament and of the council of 27 April 2016 on the protection of natural persons with regard to the processing of personal data and on the free movement of such data, and repealing directive 95/46/EC (general data protection regulation) (text with EEA relevance)", available at: https://eur-lex.europa.eu/eli/reg/2016/679/oj (accessed 26 November 2019). 
Sharma, M. (2019), "Augmented intelligence: a way for helping universities to make smarter decisions”, in Rathore, V.S., Worring, M., Mishra, D.K., Joshi, A. and Maheshwari, S. (Eds), Emerging Trends in Expert Applications and Security, Springer, Singapore, pp. 89-95.

Skagestad, P. (1993), "Thinking with machines: intelligence augmentation, evolutionary epistemology, and semiotic", Journal of Social and Evolutionary Systems, Vol. 16 No. 2, pp. 157-180.

Skiba, D.J. (2017), "Augmented intelligence and nursing”, Nursing Education Perspectives, Vol. 38 No. 2, pp. 108-109.

Sorgner, S.L. (2009), "Nietzsche, the overhuman, and transhumanism", Journal of Evolution and

Augmented intelligence technology Technology, Vol. 20 No. 1, pp. 29-42.

Tuncel, Y. (Ed.) (2017), Nietzsche and Transhumanism: Precursor or Enemy?, Cambridge Scholars Publishing, Newcastle upon Tyne.

Van Dijk, J. (2017), "Digital divide: impact of access", The International Encyclopedia of Media Effects, available at: https://www.utwente.n//en/bms/vandijk/publications/digital_divide_impact_access. pdf (accessed 20 July 2019).

Von Ahn, L. (2013), "Augmented intelligence: the Web and human intelligence", Philosophical Transactions of the Royal Society A: Mathematical, Physical and Engineering Sciences, Vol. 371, available at: https://doi.org/10.1098/rsta.2012.0383 (accessed 11 July 2019).

\begin{abstract}
About the author
Magdalena Wójcik is an assistant professor at the Jagiellonian University, Kraków (Poland). She is interested in new technologies, particularly Web 2.0, augmented reality, wearable computing and Internet of things and their impact on libraries' services. Some of her publications are: The Use of Web 2.0 Services by Urban Public Libraries in Poland: Changes over the Years 2011-2013. Libri, Vol. 65, Issue 2, pages 91-103, Potential use of Augmented Reality in LIS education. Education and Information Technologies, 21(6), pages 1,555-1,569, Internet of Things - potential for libraries, Library Hi Tech, Vol. 34 , Issue 2, pages 404-420 and Holograms in libraries - the potential for education, promotion and services. Library Hi Tech 36.1, pages 18-28. Magdalena Wójcik can be contacted at: magda.wojcik@uj. edu.pl
\end{abstract}

For instructions on how to order reprints of this article, please visit our website:

www.emeraldgrouppublishing.com/licensing/reprints.htm

Or contact us for further details: permissions@emeraldinsight.com 